\title{
Formulation, Characterization, and Herbal Drug Delivery Applications of Ethosome, Transfersome, and Transethosome
}

\author{
Luthfia Azzahra1, Soraya R. Mita ${ }^{2 *}$, Sriwidodo \\ ${ }^{1}$ Faculty of Pharmacy, Padjadjaran University, Sumedang, Indonesia \\ ${ }^{2}$ Department of Pharmaceutics and Pharmaceutical Technology, Faculty of Pharmacy, Padjadjaran \\ University, Sumedang, Indonesia
}

Received : 06 Sept 2020, Revised : 09 Sept 2020, Accepted : 20 Sept 2020, Published : 29 Des 2020

\begin{abstract}
Herbal compounds have different physicochemical properties. Its use on the oral route often has low biological availability. Therefore, alternative transdermal routes are used through the skin. The stratum corneum skin layer is the most difficult layer to penetrate. Therefore it is necessary to use a drug delivery system such as ethosome, transfersome or transethosome to increase transdermal drug delivery. This review article aims to look at the potential of ethosome, transfersome, and transethosome in increasing their ability to deliver herbal drugs in terms of their formulation and characterization. Literature searches were performed using online search engines namely NCBI and Google Scholar with the keywords 'Transdermal Drug Delivery System', 'Ethosome', 'Transfersome', and 'Transethosome'. The result showed compositions of ethosomes are phospholipids, water, and ethanol. The composition of transfersome is phospholipid, water, and edge activator. Transethosomes are a combination of phospholipids, water, ethanol, and edge activators. The role of ethanol and edge activator is thought to increase skin permeation. Transdermal drug delivery systems can be used on herbal drugs to increase transdermal drug delivery.
\end{abstract}

Keywords: Transdermal, Ethosome, Transfersome, Transethosome, Herbal.

\section{Introduction}

Currently, the use of herbal compounds as active substances in medicine is increasing rapidly. There are many active substances derived from plants. These active substances have different physicochemical properties. Catechin by oral route has low bioavailability due to poor membrane permeability and low absorption on the gastrointestinal tract $(1,2)$. Curcumin by oral route has a high rate of metabolism and poor absorption which limits the bioavailability, and it has a poor solubility on water (3). Resveratrol, a phenolic compound, by oral route has low bioavailability due to low intestinal absorption and catabolism (4). Fisetin by oral route has low bioavailability (44.1\%) (5), it is lipophilic and goes through enzymatic degradation also first-pass metabolism $(6,7)$. Capsaicin or CAP is lipophilic which affects its oral bioavailability and its intravenous half-life is very short (7.06 minutes) (8). Apigenin has low bioavailability due to its poor water solubility (9). This limits the potential pharmacological activity of the active substances. Many phyto-compounds are dealing with the same problems mentioned above.

In order to improve its bioavailability, to avoid the first-pass metabolism and enzymatic 
degradation, a transdermal route through the skin is used. In the transdermal system, drugs penetrate from the outermost layer to the blood vessels through the layers of the skin (10). Transdermal drug delivery systems have many advantages, for example, avoidance of first-pass metabolism by the liver (first-pass effect/pre-metabolism), controlled delivery of medications, and improved patient compliance, as they are noninvasive and can easily be self-administered, with transdermal drug delivery system, the drug can avoid degradation in the gastrointestinal tract (11). Several things need to be underlined is as drug's bioactivity, skin characteristic, formulation utilized, the adhesive that will be used, and the physicochemical factors affecting penetration process through the skin (12).

Stratum corneum as the main challenge is hydrophobic. Drug delivery tools such as ethosome, transfersome, and transethosome can be utilized on the transdermal route (11).

This development occurs to increase drug permeation, optimize the work of the existing drug, improve patient compliance, therapeutic index, and bioavailability of drugs (13). The present review will focus on formulation including preparation and characterization results of ethosome, transfersome, and transethosome as transdermal herbal drug delivery system.

\section{Method}

This review compiled studies published in various databases which are PubMed (NCBI) and Google Scholar. Studies obtained using the keywords "Ethosome", "Transfersome", "Transethosome", "Skin", and "Herbal". Articles published before 2010, reviews, non-English studies, and unrelated studies, such as routes other than the transdermal route and not including characterization results, were excluded. From 284 studies obtained in April-May 2020, we included 21 studies in this review.

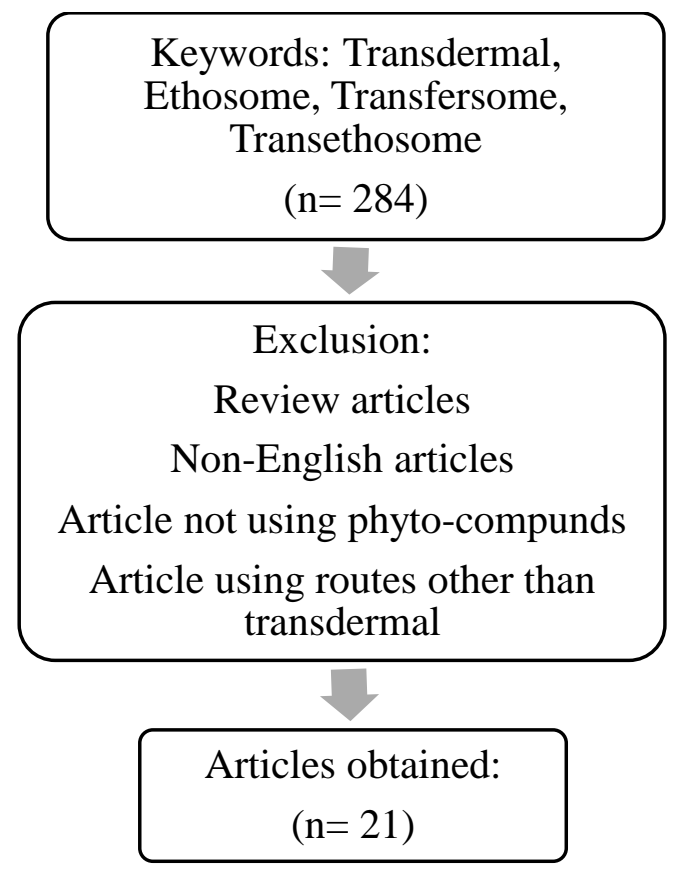

Figure 1. Flowchart of Methodology

\section{Result}

The results of the formulation can be seen in Table 1

Table 1. Formulation Result

\begin{tabular}{lllll}
\hline & Formulation & Characterization & Application & References \\
\hline Ethosome & Consists of & The characterization & Many researches & $(20-31)$ \\
water, & can be done by used ethosome as & \\
phospholipid, running several tests herbal drug & and ethanol. & such as particle size, delivery system, \\
& polydispersity index, 12 journals were \\
& zeta potential, obtained. The \\
& entrapment efficiency research showed \\
& and vesicle structures. great results and
\end{tabular}




\begin{tabular}{|c|c|c|c|}
\hline & & $\begin{array}{l}\text { The characterization } \\
\text { results from ethosome } \\
\text { as drug delivery } \\
\text { system showed good } \\
\text { results. }\end{array}$ & $\begin{array}{l}\text { ethosome } \\
\text { improves the drug } \\
\text { delivery. }\end{array}$ \\
\hline Transfersome & $\begin{array}{l}\text { Consists of } \\
\text { water, } \\
\text { phospholipid, } \\
\text { and edge } \\
\text { activator. }\end{array}$ & $\begin{array}{l}\text { The characterization } \\
\text { can be done by } \\
\text { running several tests } \\
\text { such as particle size, } \\
\text { polydispersity index, } \\
\text { zeta potential, } \\
\text { entrapment efficiency } \\
\text { and vesicle structures. } \\
\text { The characterization } \\
\text { results from } \\
\text { transfersome as drug } \\
\text { delivery system } \\
\text { showed good results. }\end{array}$ & $\begin{array}{l}\text { Many researches } \\
\text { used transfersome } \\
\text { as herbal drug } \\
\text { delivery system, } 7 \\
\text { journals } \quad \text { were } \\
\text { obtained. The } \\
\text { research showed } \\
\text { great results and } \\
\text { transfersome } \\
\text { improves the drug } \\
\text { delivery. }\end{array}$ \\
\hline Transethosome & $\begin{array}{l}\text { Consists of } \\
\text { water, } \\
\text { phospholipid, } \\
\text { ethanol, and } \\
\text { edge } \\
\text { activator. }\end{array}$ & $\begin{array}{l}\text { The characterization } \\
\text { can be done by } \\
\text { running several tests } \\
\text { such as particle size, } \\
\text { polydispersity index, } \\
\text { zeta potential, } \\
\text { entrapment efficiency } \\
\text { and vesicle structures. } \\
\text { The characterization } \\
\text { results from } \\
\text { transethosome as drug } \\
\text { delivery system } \\
\text { showed good results. }\end{array}$ & $\begin{array}{l}\text { There are only a (38-39) } \\
\text { few research used } \\
\text { transethosome as } \\
\text { drug delivery } \\
\text { system, } 2 \text { journals } \\
\text { were obtained. The } \\
\text { research showed } \\
\text { great results and } \\
\text { transethosome } \\
\text { improves the drug } \\
\text { delivery. }\end{array}$ \\
\hline
\end{tabular}

\section{Discussion}

The transdermal drug delivery system; ethosome, transfersome, and transethosome has basic composition which is phospholipid and water. Ethanol is used in ethosome and transethosome, edge activator is used in transfersome and transethosome. The phosphatidylcholine head is water-soluble and the tail part is lipid-soluble (14).

Transfersome contains water, phospholipid (lipid bilayer), and edge activator. Ethosome contains water, phospholipid (lipid bilayer), and ethanol. Transethosome fuses ethanol and edge activator as a penetration enhancer, and water and phospholipid as vesicle former.

\section{Mechanism of penetration}

Ethosome has a penetrating mechanism into the skin. Ethanol in the ethosome penetrates intracellular lipids and escalates the fluidity of cell membrane lipids, besides decreasing the level of lipid density of the membrane cell layer, so that the active substance in the ethosome can penetrate through the stratum corneum, the outer layer of skin which is lipophilic (16). Also, the ethanol and phospholipid content in ethosomes increases the elasticity of the ethosomal vesicles so that they can penetrate deeper (15). The penetration mechanism of transfersome is the vesicles maintain their structure or it fuses with the lipid layers of skin (17). Transfersome can easily change their shape to 
cross the skin layer due to the edge activator action responding to mechanical stress, directing inside the vesicle to a region with a smaller curve, reducing the membrane elastic energy to a minimum level (18). Transfersome can slide through small channels, crossing the stratum corneum (19).

Table 2. Application of Ethosome

\begin{tabular}{|c|c|c|c|}
\hline No. & Phyto-compound/Plants & $\begin{array}{l}\text { Ethanol } \\
\text { concentration }\end{array}$ & Reference \\
\hline 1. & $\begin{array}{l}\text { EGCG (Camellia sinensis } \\
\text { L. Kuntze) }\end{array}$ & Ethanol 95\% (5\%) & (20) \\
\hline 2. & $\begin{array}{l}\text { Curcumin (Rhizoma } \\
\text { Curcumae Longae) }\end{array}$ & $\begin{array}{l}\text { Ethanol:Water } \\
(3: 7)\end{array}$ & (21) \\
\hline 3. & $\begin{array}{l}\text { Charantin (Momordica } \\
\text { charantial Linn.) }\end{array}$ & Ethanol 96\% (30\%) & (22) \\
\hline 4. & Capsaicin & Ethanol $(75 \%)$ & $(23)$ \\
\hline 5. & $\begin{array}{l}\text { Eugenol } \quad \text { (Sygizium } \\
\text { aromaticum) }\end{array}$ & Ethanol (30\%) & (24) \\
\hline 6. & $\begin{array}{l}\text { Apigenin } \quad \text { (Petroselinum } \\
\text { crispum) }\end{array}$ & $\begin{array}{l}\text { Ethanol:PEG (20- } \\
50 \%)\end{array}$ & $(25)$ \\
\hline 7. & $\begin{array}{l}\text { Sesamum indicum L. Seed } \\
\text { extract }\end{array}$ & Ethanol (10-40\%) & (26) \\
\hline 8. & Seabuckthorn leaf extract & Ethanol (40\%) & $(27)$ \\
\hline 9. & $\begin{array}{l}\text { Sophocarpine } \quad \text { (Sophora } \\
\text { alopecuroides) }\end{array}$ & Ethanol (10\%) & $(28)$ \\
\hline 10. & $\begin{array}{l}\text { Cryptotanshinone (Salvia } \\
\text { miltiorrhiza) }\end{array}$ & Ethanol (30-40\%) & (29) \\
\hline 11. & Phenylethyl Resorcinol & Ethanol $(30 \%)$ & $(30)$ \\
\hline 12. & $\begin{array}{l}\text { Mangiferin (Mangifera } \\
\text { indica) }\end{array}$ & Ethanol (20\%) & (31) \\
\hline
\end{tabular}

\section{EGCG (Camellia sinensis L. Kuntze)}

Epigallocatechin gallate (EGCG) has low penetration, ethosome is used with mechanical dispersion and thin layer hydration (TLH) method. Ethanol $95 \%$ on $5 \%$ concentration was used. Characterization results showed ethosome had a spherical shape, polydispersity index 0.05 which was qualified, zeta potential range was $-60.00 \mathrm{mV} /-$ $67.00 \mathrm{mV}$, which proven its stability (20).

\section{Curcumin (Rhizoma Curcumae Longae)}

Due to curcumin's low water solubility (lipophilic), several transdermal drug delivery systems were prepared (Propylene glycol liposomes (PGL), Liposomes, and Ethosome).
Ethanol injection method was used. Ethosome used ethanol:water 3:7, PGL used propylene glycol as a penetration enhancer. Results showed ethosome particle size was $289 \pm$ $132,1 \mathrm{~nm})$ and entrapment efficiency was $57,9 \pm 4.72 \%$ PGL had the smallest particle size $(182.4 \pm 89.2 \mathrm{~nm})$, spherical, good particle distribution, and showed no aggregation. Ethosome had small aggregation using the method earlier. The entrapment efficiency of PGL showed the highest rate of $>90 \%$. PGL has the highest potential as a transdermal drug delivery system (21).

3. Charantin (Momordica charantial Linn.)

Charantin have low penetration through the skin; to overcome this, ethosome was used 
as a transdermal delivery system. The method used was TLH. Ethanol $96 \%$ equal $30 \%$ on the formulation was used. Characterization results showed ethosome had a spherical shape, particle size $1083.33 \pm 15.27 \mathrm{~nm}$, polydispersity index $(0.42 \pm 0.02)$, stable (zeta potential $-54.33 \pm 0.75 \mathrm{mV})$, and entrapment efficiency $91.50 \pm 0.40 \%$. Ethosome is highly potential as a transdermal drug delivery system for charantin (22).

\section{Capsaicin}

Capsaicin loaded ethosome were prepared using four different methods, which are the hot method, cold method, classic method, and injection method. Characterization results showed the hot method to be the most effective with high stability, spherical shape $(50-300 \mathrm{~nm})$, EE $81.40 \%$, zeta potential $4.28+4.07 \mathrm{mV} \mathrm{mV}$, homogenous, and uniform distribution using $75 \%$ ethanol on the formulation (polydispersity index 0.162) (23).

\section{Eugenol (Sygizium aromaticum)}

Eugenol loaded ethosome was prepared using the hot method. Ethanol used in the formulation equal to $30 \%$ The result showed that eugenol concentration influenced particle size and entrapment efficiency. Particle size $44.21 \mathrm{~nm}$, zeta potential $-40.3 \pm 1.7 \mathrm{mV}$, polydipersity index $0.189 \pm 0.051$, and EE $82 \%$. Ethosome is highly potential for the transdermal delivery system (24).

\section{Apigenin (Petroselinum crispum)}

Apigenin loaded ethosome was prepared using the classic injection method. Ethanol:Propylene glycol was used as penetration enhancer with various concentration $(20-50 \%)$. The result showed encapsulation efficiency increase with phospholipid concentration. Particle size ranged from $36.61 \pm 1.78$ to $698.33 \pm 124.30$ $\mathrm{nm}$, zeta potential $10.14 \pm 2.04$ and $27.67 \pm$ $3.23 \mathrm{mv}$, EE ranged from 61.69-85.21\%. Phospholipid and ethanol concentration improved skin deposition. Optimized ethosome showed better activity rather than basic liposomes. It is highly potential (25).

\section{Sesamum indicum L. Seed extract}

Ethosome were used as a transdermal delivery system to reduce the pre-metabolism effect on Sesamum indicum. The method used was solvent dispersion or cold method. Ethanol used in the formulation ranged from 10-40\%. Characterization result showed a good polydispersity index (0.114 to 0.348$)$, and $\mathrm{ZP}$ were between $-17.0 \mathrm{mV} / 47.7 \mathrm{mV}$, stable according to zeta potential result, the shape was spherical $(139.7 \pm 10.55-231.8 \pm$ $12.43 \mathrm{~nm})(26)$.

\section{Seabuckthorn leaf extract}

Seabuckthorn leaf, contain phenolic active substances. Ethosome were used as a transdermal delivery system. The cold method with modification was used. Ethanol used in the formulation ranged from $10-40 \%$. The result showed ethosome had a smooth surface, vesicle size 96.98-395 $\mathrm{nm}$, polydispersity index $0.041-0.392$, formulation of $40 \%$ ethanol, $3 \%$ phospholipid, and $75 \%$ ethanolic extract showed good entrapment efficiency, $91.09 \pm 0.64 \%$ (27).

\section{Sophocarpine (Sophora alopecuroides)}

Sophora alopecuroides loaded ethosome were prepared used the transmembrane $\mathrm{pH}$ Gradient method with $10 \%$ ethanol. Particle size $142 \pm 15.5 \mathrm{~nm}$ and EE more than $90 \%$. The result showed good entrapment efficiency; the method successfully enhanced the stability and drug delivery (28).

\section{Cryptotanshinone (Salvia miltiorrhiza) \\ Ethosome loaded cryptotanshinone} (CPT) was prepared using the classic method. Ethanol as penetration enhancer was used (30$40 \%$ ). The characterization result showed vesicle had good vesicle size $(69.1 \pm 1.9 \mathrm{~nm})$, polydispersity index $0.185 \pm 0.017$, and $\mathrm{EE}$ was $40.31 \pm 0.67 \%$. Ethosome formulation is an 
effective dermal delivery system and highly promising for the future (29).

\section{Phenylethyl Resorcinol}

Phenylethyl Resorcinol (PR) had poor water solubility and low stability. Ethosome is used as a transdermal delivery system to protect active substances using 30\% absolute ethanol. TLH is used to prepare the vesicle. The particle size range was $214-890 \mathrm{~nm}$; the phospholipid concentration increased the vesicle size, contrary to ethanol. The zeta potential range was $-33 \mathrm{mV}$ to $-35.6 \mathrm{mV}$. EE was higher than $50 \%$ (30).

\section{Mangiferin (Mangifera indica)}

Ethosome is used to increase the bioavailability of Mangifera indica extract. The hot method was used to prepare ethosome using $20 \%$ ethanol. The EE range was 65.31 $89.38 \%$. The zeta potential score was $8.8 \mathrm{mV}$. The average size was $926 \mathrm{~nm}$ (31).

Table 3. Application of Transfersome

\begin{tabular}{llll}
\hline No. & Phyto-compound/Plants & Edge activator & References \\
\hline 1. & Resveratrol & Tween 80, Tween 20 & $(32)$ \\
\hline 2. & $\begin{array}{l}\text { EGCG (Camellia sinensis L. } \\
\text { Kuntze) }\end{array}$ & Span 80 & $(33)$ \\
\hline 3. & Parkia speciosa Hassk. Extract & Tween 80 & $(34)$ \\
\hline 4. & Resveratrol & Sodium cholate & $(35)$ \\
\hline 5. & $\begin{array}{l}\text { Berberine, Berbamine (Berberis } \\
\text { aristata) }\end{array}$ & Span 80 : PC (15:85) & $(36)$ \\
\hline 6. & Quercetin & Tween 80 & $(37)$ \\
\hline 7. & $\begin{array}{l}\text { Quercetin flavonoids (Malus } \\
\text { domestica } \text { Mill) }\end{array}$ & Span 80 & $(33)$ \\
\hline
\end{tabular}

\section{Resveratrol}

Resveratrol, polyphenol active substances used transfersome as a transdermal delivery system. A non-ionic edge activator is used such as Tween 80 and Tween 20. Particle size $40.13 \pm 0.51 \mathrm{~nm}$, spherical shaped. Polydispersity index was $0.266 \pm 0.009$, zeta potential was $-23.93 \pm 0.31 \mathrm{mV}$, and $\mathrm{EE}$ was $59.01 \pm 1.02 \%$. The stability and solubility were improved (32). Another research conducted by (35) using an edge activator, sodium cholate. Characterization result showed particle size $105.4 \pm 7.9$, poldispersity index 0.1 , zeta potential $-22.4 \pm 0.2 \mathrm{mV}$ (35).

\section{EGCG (Camellia sinensis L. Kuntze)}

Green tea contains epigallocatechin gallate (EGCG). EGCG loaded transfersome were prepared using a TLH method. Span 80 was used as edge activator. The result showed ethosome had a spherical shape (107.82 \pm 0.44 $\mathrm{nm})$, good polydispersity index $(0.07 \pm 0.01)$, stable (zeta potential $-40.3 \pm 1 \mathrm{mV}$ ) and EE was $63.16 \pm 0.65 \%$. EGCG loaded ethosome showed better in vitro penetration rather than the non-transfersome one (38)(39).

\section{Parkia speciosa Hassk. Extract}

Parkia speciosa has flavonoids and phenolics active substances which are difficult to penetrate through the skin, to overcome this, transfersome were used as a transdermal delivery system. Tween 80 was used as an edge activator. The method used for transfersome preparation was TLH. The result showed spherical shape, particle size 495.6 $\mathrm{nm}$, polydispersity index 0,484 . Zeta potential $-21.4 \mathrm{mV}$. EE was $91.6884 \pm 0.0261 \%$. Overall the Parkia speciosa extract loaded ethosome showed better stability and more soluble than the pure extract (34). 
4. Berberine, Berbamine (Berberis aristata)

Berberis aristata has antipsoriatic activity. To develop it, transfersome were used as a transdermal delivery system. The method used is lipid film hydration, using different edge activator (Tween 80, Span 80, and sodium deoxycholate). Characterization showed $330 \pm 19 \mathrm{~nm}$ particle size and the polydispersity index was $0.29 \pm 0.007$, and zeta potential range was $-35.2 \mathrm{mV}$. EE was $78.0 \pm 1.12 \%$. It is highly potential compared to conventional drugs (36).

\section{Quercetin}

Quercetin loaded transfersome were prepared using the injection method. Edge activators used were Tween-80, sodium cholate, sodium decanoate, and sodium oleate). Transfersomes with Tween-80 led to high zeta potential $[(-38.0 \pm 1.5) \mathrm{mV}]$, cumulative permeation were $(9.37 \pm 2.59)$ and remarkably enhances the cumulative permeation and retention (37).

\section{Quercetin flavonoids (Malus domestica Mill)}

Transfersome as a transdermal delivery system were used. The preparation used a TLH, using Span 80 as an edge activator. The result showed a good polydispersity index (0.078-0.273), particle size $106.44 \pm 2.70 \mathrm{~nm}$, and zeta potential of $-49.96 \pm 2.05 \mathrm{mV}$, EE was $78.78 \pm 0.46 \%$. proofing the stability of the vesicle (33).

Table 4. Application of Transethosome

\begin{tabular}{lllll}
\hline No. & Phyto-compound/Plants & Ethanol and Edge activator & References \\
\hline 1. & Fisetin (Cucumis sativus) & $\begin{array}{l}\text { Ethanol and Sodium } \\
\text { Cholate }\end{array}$ \\
\hline 2. & EGCG (Camellia sinensis & L. & Ethanol and Span 80 & (39) \\
& Kuntze)
\end{tabular}

1. Fisetin

Fisetin used transethosome as a transdermal delivery system. Ethanol and edge activator (Sodium cholate) was used as a penetration enhancer. The thin lipid film method was used in the preparation. Results showed good characterization, vesicle size of $74.21 \pm 2.65 \mathrm{~nm}$, zeta potential of $11.0 \mathrm{mV}$, entrapment efficiency of $68.31 \pm 1.48 \%$. Transethosomes vesicles formulation was found to be a potentially useful drug carrier for fisetin dermal delivery (38).

\section{Green tea (EGCG)}

Transethosome was used as a transdermal delivery system using a TLH method. Span 80 and ethanol were used as a penetration enhancer. Transethosome with green tea extract equivalent to 3\% EGCG, 4\% Lipoid P30, $0.75 \%$ Span 80, and 30\% ethanol had the best characteristic including spherical shape, smallest particle size $(35.35 \mathrm{~nm}), 0.319$ PDI, and zeta potential of $-29.97 \pm 3.05 \mathrm{mV}$. EE was $45.26 \% \pm 8.15 \%$. Transethosome can increase the skin penetration of green tea leaf extract (39).

\section{Formulation}

The formulation of ethosome, transfersome, and transethosome varies. The ethanol in ethosome cause the ethosome to become elastic, encourages the vesicles shape and increase the stability, with the increasing concentration of ethanol, the vesicle size would decrease (14), but increasing ethanol concentration above the optimum level would increase the vesicle size, also decreasing the entrapment efficacy and it would cause a leak, moreover it could solubilize the vesicle structure. 
The phospholipid is a vesicle forming component. There is synthetic and natural phospholipid. It is important to choose the right type of phospholipid because it can affect the size, zeta potential, stability, entrapment efficacy, and the penetration of vesicles. Generally, the phospholipids concentration range is $0.5 \%-5 \%$ (30). The higher the concentration, the vesicle size will moderately get bigger. The entrapment efficiency will increase significantly in a certain concentration (40).

Edge activators are surfactants. It has a high span of curvature. It can destabilize the lipid bilayers and builds the deformability of the bilayers of the vesicles. Many research concluded edge activators improve skin penetration, and it affects the charge and particle size of vesicles. Another edge activator is dimethyl sulfoxide; it enhances the penetration in a topical formulation. Tween 80 at $10 \%-50 \%$ concentration was reported to reduce the size of the vesicle and increase the vesicle stability and skin permeation properties, it mainly solubilizes the system and prevents vesicle fusion. Other edge activators such as oleic acid affect the vesicular size, zeta potential, elasticity, and permeation on the skin by increasing the fluidity of the stratum corneum $(21,30,41,42)$.

\section{Preparation}

Thin layer hydration

The phospholipid and other lipophilic substances dissolved in ethanol, the aqueous phase was sonicated at $60^{\circ} \mathrm{C}$ for 30 minutes. The lipid phase poured to a round-bottomed flask and then it was evaporated to remove the ethanol. The lipid film was hydrated with aqueous phase in a closed container, and then it was sonicated at $60^{\circ} \mathrm{C}$ for 30 minutes (30).

\section{Hot method}

Lipids are dispersed into the water at $40^{\circ} \mathrm{C}$ to form a colloidal phase. In different containers, edge activator/ethanol and glycol are mixed. The active substance is mixed into an appropriate solubility solvent. The organic phase is poured into the aqueous phase, then stirs the mixture until it's evenly mixed (43).

\section{Cold method}

The active substance, phospholipid, edge activator/ethanol, and glycol are mixed and stirred vigorously with a mixer until dissolved then heated to a temperature of $30^{\circ} \mathrm{C}$. In different containers, the water is heated to a temperature of $30^{\circ} \mathrm{C}$. Then mix the water into the ethanol mixture, stir vigorously (43).

\section{Classic method}

Phospholipids and plant extracts are dissolved into edge activator/ethanol, and then heated $30^{\circ} \mathrm{C}$. Add redistilled water, stir at a speed of $700 \mathrm{rpm}$. Vesicles are homogeneous by passing them on a polycarbonate membrane (43).

\section{Mechanical dispersion method}

Phospholipids and plant extracts are dissolved in chloroform: ethanol 3: 1 and/or edge activator. The organic solvent is evaporated with a vacuum evaporator, then vacuum for 1 night after that, it was hydrated to obtain ethosomes (43). The size of the ethosome can be adjusted by sonication or extrusion. (44).

\section{Sonication}

The use of sonication with high intensity can induce chemically and physically. The physical effect of sonication is emulsification, usually used for dispersion of fillers in basic polymers and emulsification of inorganic particles in polymers. The chemical effect of sonication is to cause molecules to interact, which then causes chemical changes. The interaction is based on ultrasonic wavelengths that are higher than the wavelengths of molecules. In sonication, a sonicator probe or ultrasonic bath can be used. In this method, a uniform ethosome suspension is produced. According to research conducted by (45) that the size of the vesicles produced by sonication is smaller than the extrusion method. However, the efficiency of vesicle sorption carried out by the extrusion method is higher than sonication (45).

\section{Extrusion}

In extrusion, it is normally done by consecutively extruding the ethosome vesicle 
system under moderately low pressure for quite a while or a cycle going through a polycarbonate membrane with a pore size of $50-400 \mathrm{~nm}$. Nonetheless, in this method there are two ways, extrusion should be possible by extruding several times through one membrane with one pore size or can be done in stages with a membrane that is stacked with different sizes of pores. By shrinking the pore size of the membrane, the size of the ethosome produced will shrink as well. The outcome of the process is a more uniform size of the colloid ethosome with a low polydispersity index value (40).

\section{Characterization}

The efficiency of drug sorption can be measured by ultracentrifugation techniques, small centrifugation columns, and also the fluorescence spectrophotometer. The stability is evaluated based on sorption efficiency and particle size, this depends on the composition of the phospholipids in the vesicle (46). The table below shows the minimum and maximum number for each characterization of the vesicular system $(20,47)$ :

Characterization needs to be done to confirm that the vesicle qualified and stable.

Table 5. Characterization

\begin{tabular}{llll}
\hline No. & Characterization & Score & References \\
\hline 1. & Particle size & $<300 \mathrm{~nm}$ & $(20,47)$ \\
\hline 2. & Polydispersity index & $0-0,5$ & $(20,47)$ \\
\hline 3. & Zeta potential & $>+30 \mathrm{mV}$ or $<-30 \mathrm{mV}$ & $(20,47)$ \\
\hline
\end{tabular}

\section{Particle Size Analyzer}

Particle Size Analyzer is a common method that is widely used for image analysis. PSA usually uses a wet method which is considered more accurate when compared to the dry method or the sieve method and image analysis. Nanoparticle samples tend to have high agglomeration (easy to clot) so that it is more suitable to use the wet method. The wet method will provide measurable results in the form of distribution, where the measurement results are assumed to describe all sample conditions (48).

\section{Zeta Potential}

Zeta potential is a measure of the magnitude of the electrostatic charge of particles in dispersion, following the study of the stability of nanoparticle suspension. Zeta potential above the absolute value of $30 \mathrm{mV}$ is called obligatory to assure fine colloidal stability (49). Zeta potential has a role in physical stability; zeta nanoparticle potential also influences the effectiveness of vesicles as a drug conductor (50).

\section{Transmission Electron Microscopy}

In the standard TEM operation mode, which is generally alluded to as amplitude or contrast-diffraction imaging, only a tiny bit of electrons that have gone through the sample is utilized to shape the final image that is greatly enlarged (51).

\section{Conclusion}

The transdermal drug delivery system above proved their potential to deliver many phyto compound derived from plants with different physicochemical properties. The formulation, which is penetration enhancer such as ethanol and edge activator improves the characterization result.

\section{References}

1. Giudicessi JR, Ackerman MJ. Determinants of incomplete penetrance and variable expressivity in heritable cardiac arrhythmia syndromes. Transl Res. 2013;161(1):1-14.

2. McClements DJ. Encapsulation, protection, and release of hydrophilic active components: Potential and limitations of colloidal delivery systems. Adv Colloid Interface Sci. 2015;219:2753.

3. Zhang L, Zhu W, Yang C, Guo H, Yu A, Ji J, et al. A novel folate-modifed 
self-microemulsifying drug delivery system of curcumin for colon targeting. Int J Nanomedicine. 2012;7:151-62.

4. de Oliveira MTP, Coutinho D de S, de Souza ÉT, Guterres SS, Pohlmann AR, Silva PMR, et al. Orally delivered resveratrol-loaded lipid-core nanocapsules ameliorate LPS-induced acute lung injury via the ERK and PI3K/Akt pathways. Int $\mathbf{J}$ Nanomedicine. 2019;14:5215-28.

5. Seguin J, Brullé L, Boyer R, Lu YM, Ramos Romano M, Touil YS, et al. Liposomal encapsulation of the natural flavonoid fisetin improves bioavailability and antitumor efficacy. Int J Pharm. 2013;444(1-2):146-54.

6. Bothiraja C, Yojana BD, Pawar AP, Shaikh KS, Thorat UH. Fisetin-loaded nanocochleates: Formulation, characterisation, in vitro anticancer testing, bioavailability and biodistribution study. Expert Opin Drug Deliv. 2014;11(1):17-29.

7. Kadari A, Gudem S, Kulhari H, Bhandi MM, Borkar RM, Kolapalli VRM, et al. Enhanced oral bioavailability and anticancer efficacy of fisetin by encapsulating as inclusion complex with HP $\beta C D$ in polymeric nanoparticles. Drug Deliv. 2017;24(1):224-32.

8. Tavano L, Alfano P, Muzzalupo R, De Cindio B. Niosomes vs microemulsions: New carriers for topical delivery of Capsaicin. Colloids Surfaces B Biointerfaces. 2011;87(2):333-9.

9. Zhang J, Liu D, Huang Y, Gao Y, Qian $\mathrm{S}$. Biopharmaceutics classification and intestinal absorption study of apigenin. Int J Pharm. 2012;436(1-2):311-7.

10. Donnelly R., Singh TR., Morrow D., Woolfson A. Microneedle-Mediated Transdermal and Intradermal Drug Delivery. Hoboken, New Jersey: Wiley; 2012.

11. Pirvu CD, Hlevca C, Ortan A, Prisada R. Elastic vesicles as drugs carriers through the skin. Farmacia. 2010;58(2):128-35.

12. Kalpana S P, Mikolaj M, Courtney L S, Nicole K B, Priyanka G, Audra L S.
Challenges and opportunities in dermal/transdermal delivery. Ther Deliv. 2010;11(11083):109-31.

13. Almandil NB. Healthcare professionals' awareness and knowledge of adverse drug reactions and pharmacovigilance. Saudi Med J. 2016;37(12):1350-5.

14. Touitou E, Dayan N, Bergelson L, Godin B, Eliaz M. Ethosomes - Novel vesicular carriers for enhanced delivery: Characterization and skin penetration properties. J Control Release. 2000;65(3):403-18.

15. Romero EL, Morilla MJ. Highly deformable and highly fluid vesicles as potential drug delivery systems: Theoretical and practical considerations. Int J Nanomedicine. 2013;8:3171-86.

16. Dave V, Kumar D, Lewis S, Paliwal S. Ethosome for enhanced transdermal drug delivery of aceclofenac. Int J Drug Deliv. 2010;2(1):81-92.

17. Chen J, Lu WL, Gu W, Lu SS, Chen ZP, Cai BC. Skin permeation behavior of elastic liposomes: Role of formulation ingredients. Expert Opin Drug Deliv. 2013;10(6):845-56.

18. Elsayed MMA, Cevc G. The vesicle-tomicelle transformation of phospholipidcholate mixed aggregates: A state of the art analysis including membrane curvature effects. Biochim Biophys Acta - Biomembr. 2011;1808(1):140-53.

19. Cevc G, Vierl U, Mazgareanu S. Functional characterisation of novel analgesic product based on selfregulating drug carriers. Int $\mathrm{J}$ Pharm. 2008;360(1-2):18-28.

20. Makula A, Maddela R, Pilli NR, Maddela S, Pulipati CR, Polagani SR. A novel and Rapid LC-MS/MS assay for the Determination of Mycophenolate and Mycophenolic Acid in Human Plasma. J Young Pharm. 2017;9(1):10714.

21. Zhao YZ, Lu CT, Zhang Y, Xiao J, Zhao YP, Tian JL, et al. Selection of high efficient transdermal lipid vesicle for curcumin skin delivery. Int $\mathrm{J}$ Pharm. 2013;454(1):302-9. 
22. Surini S, Arnedy AR, Iswandana R. Development of ethosome containing bitter melon (Momordica charantia Linn.) fruit fraction and in Vitro skin penetration. Pharmacogn J. 2019;11(6):1242-51.

23. Majeed I, Raza SA, Akhtar N, Siddiqui FA, Iqbal B. Formulation and in-vitro characterization of Capsaicin loaded ethosomes. Pak J Pharm Sci. 2019;32(6):2849-57.

24. Jin P, Yao R, Qin D, Chen Q, Du Q. Enhancement in Antibacterial Activities of Eugenol-Entrapped Ethosome Nanoparticles via Strengthening Its Permeability and Sustained Release. J Agric Food Chem. 2019;67(5):1371-80.

25. Shen LN, Zhang YT, Wang Q, Xu L, Feng NP. Enhanced in vitro and in vivo skin deposition of apigenin delivered using ethosomes. Int $\mathbf{J}$ Pharm. 2014;460(1-2):280-8.

26. Somwanshi SB, Hiremath SN. Development and evaluation of novel ethosomal vesicular drug delivery system of Sesamum indicum L. seed extract. Asian J Pharm. 2018;12(4):S1282-90.

27. Nimisha, Srivastava K, Singh AK. Formulation and evaluation of seabuckthorn leaf extract loaded ethosomal gel. Asian J Pharm Clin Res. 2015;8(5):309-12.

28. Zhou Y, Wei Y, Liu H, Zhang G, Wu X. Preparation and in vitro evaluation of ethosomal total alkaloids of Sophora alopecuroides loaded by a transmembrane $\mathrm{pH}$-gradient method. AAPS PharmSciTech. 2010;11(3):13508.

29. Yu Z, Lv H, Han G, Ma K. Ethosomes Loaded with cryptotanshinone for acne treatment through topical gel formulation. PLoS One. 2016;11(7):111.

30. Limsuwan T, Boonme P, Khongkow P, Amnuaikit T. Ethosomes of Phenylethyl Resorcinol as Vesicular Delivery System for Skin Lightening Applications. Biomed Res Int. 2017;2017.
31. Sundari BT, Rao PS, Sireesha K, Sai YK, Sundari BT, Sireesha K, et al. Formulation and Evaluation of Ethosomal Gels of Mangifera Indica Leaf Extract. 2017;4(06):1755-61.

32. Wu PS, Li YS, Kuo YC, Tsai SJJ, Lin CC. Preparation and evaluation of novel transfersomes combined with the natural antioxidant resveratrol. Molecules. 2019;24(3):1-12.

33. Zesiorani NF, Anwar E. Transfersome gel formulation of an ethanol extract of apples (malus domestica mill) containing antioxidants and in vitro penetration testing using franz diffusion cells. Int J Appl Pharm. 2017;9:32-7.

34. Fitrya F, Fithri NA, Winda M, Muharni M. Ethanol extract of Parkia speciosaHassk.loaded transfersome: Characterization and optimization. J Pharm Pharmacogn Res. 2020;8(3):16776.

35. Scognamiglio I, De Stefano D, Campani V, Mayol L, Carnuccio R, Fabbrocini G, et al. Nanocarriers for topical administration of resveratrol: A comparative study. Int $\mathrm{J}$ Pharm. 2013;440(2):179-87.

36. Chester K, Zahiruddin S, Ahmad A, Khan W, Paliwal S, Ahmad S. Bioautography-based Identification of Antioxidant Metabolites of Solanum nigrum L. and Exploration Its Hepatoprotective Potential agChester, K. et al. (2017) 'Bioautography-based Identification of Antioxidant Metabolites of Solanum nigrum L. and Explorati. Pharmacogn Mag. 2017;13 (Suppl(62):179-88.

37. Yaowen L, Shengyun Y, Xiaoying L, Qiuxia W. Effect of Formulation on Transdermal Delivery of Quercetin Transfersomes. CJPH. 2017;48(04):523.

38. Moolakkadath $\mathrm{T}$, Aqil $\mathrm{M}$, Ahad A, Imam SS, Iqbal B, Sultana $\mathrm{Y}$, et al. Development of transethosomes formulation for dermal fisetin delivery: Box-Behnken design, optimization, in vitro skin penetration, vesicles-skin interaction and dermatokinetic studies. 
Artif Cells, Nanomedicine Biotechnol. 2018;46(sup2):755-65.

39. Anwar E, Ramadon D, Ardi GD. Novel transethosome containing green tea (Camellia Sinensis L. Kuntze) leaf extract for enhanced skin delivery of epigallocatechin gallate: Formulation and in vitro penetration test. Int $\mathbf{J}$ Appl Pharm. 2018;10(Special Issue 1):299302.

40. Abdulbaqi IM, Darwis Y, Khan NAK, Assi RA, Khan AA. Ethosomal nanocarriers: The impact of constituents and formulation techniques on ethosomal properties, in vivo studies, and clinical trials. Int $\mathbf{J}$ Nanomedicine. 2016;11:2279-304.

41. Ascenso A, Raposo S, Batista C, Cardoso P, Mendes T, Praça F garcia, et al. Development, characterization, and skin delivery studies of related ultradeformable vesicles: transfersomes, ethosomes, and transethosomes. Int $\mathrm{J}$ Nanomedicine. 2015;10:5837-51.

42. Song CK, Balakrishnan P, Shim CK, Chung SJ, Chong S, Kim DD. A novel vesicular carrier, transethosome, for enhanced skin delivery of voriconazole: Characterization and in vitro/in vivo evaluation. Colloids Surfaces B Biointerfaces. 2012;92:299-304.

43. Fatima Grace $X$, Suganya K, Shanmuganathan S. Development of Terminalia Chebula loaded ethosomal gel for transdermal drug delivery. Asian J Pharm Clin Res. 2018;11(12):380-3.

44. Pirrung $M$. The Synthetic Organic Chemist's Companion. New Jersey:
John Wiley \& Sons Inc; 2007.

45. Maestrelli F, Capasso G, GonzálezRodríguez ML, Rabasco AM, Ghelardini C, Mura P. Effect of preparation technique on the properties and in vivo efficacy of benzocaine-loaded ethosomes. J Liposome Res. 2009;19(4):253-60.

46. Maurya SD, Prajapati SK, Gupta AK, Saxena GK, Dhakar RC. Formulation development and evaluation of ethosome of stavudine. Indian J Pharm Educ Res. 2010;44(1):102-8.

47. Pan L, Wang H, Gu K. Nanoliposomes as vehicles for astaxanthin: Characterization, in vitro release evaluation and structure. Molecules. 2018;23(11).

48. Panigrahi L, Pattnaik S, Ghosal saroj K. Design and Characterization of Mucoadhesive Buccal Patches of Salbutamol Sulphate. Acta Pol Pharm Drug Res. 2004;61(5):351-60.

49. Jonassen H. Polysaccharide based nanoparticles for drug delivery applications (Thesis). Oslo: University of Oslo; 2014.

50. Honary S, Zahir F. Effect of Zeta Potential on the Properties of NanoDrug Delivery Systems - A Review (Part 1). Trop J Pharm Res. 2013;12(2):25564.

51. Smith DJ. CHAPTER 1: Characterization of nanomaterials using transmission electron microscopy. In: Nanocharacterisation Edition: 2. 2nd ed. Arizona, USA; 2015. p. 1-29. 